Diana DiPaolo Loren

Uzi Baram

\section{Between Art and Artifact: Approaches to Visual Representations in Historical Archaeology}

\section{Introduction}

Anthropology has a long history of examining the visual, from the work of early ethnographers who used photography as part of their documentation process to the present-day critiques by visual anthropologists (Edwards 1992; Pinney 1997; Moser 2001). As David MacDougall (1997:276) notes, "Anthropology has had no lack of interest in the visual; its problem has always been what to do with it." That is, while visual images are commonly used in anthropological interpretations (such as in academic publications, conference presentations, and museum displays), researchers rarely reflect on how images function in relation to the research process. Images have had, and continue to have, an impact on how archaeologists visualize and interpret the past (Moser 2001: 266). Representations of the past (be it the deep past or more recent decades) can serve to fix visions of past peoples and their activities, even when these images have been derived from and shaped by particular colonialist, aesthetic, or nationalist schema. Current visual anthropologists argue that images can never be taken at face value, as there is always a story behind an image. Simply put, images are not a direct window to the past. Such critiques are not new to historical archaeologists, and they mirror those of ethnohistorians (for instance, Patricia Galloway) who also argue that historical texts include more than what is on the page. Such critical approaches to the ethnohistorical record are reminders that archaeologists must be mindful of origin, intent, dissemination, and audience when employing images of the recent past (Beaudry 1988; Galloway 1991; Stahl 1993).

Visual representations have an immediacy that seems to negate critical consideration. Images are often given primacy over text and artifacts. Using images is common in archaeology because they serve to confirm the material record. For example, what becomes important for many historical archaeologists is that an object found in the archaeological record is correlated to an historical image. Such correlations avoid critical issues of origin and intent, such as who is depicted and why, what ideologies are represented, who was the artist, who had access to such images, and how are such images used in the present. The lack of such a critical approach often results in a simple and naive, rather than a critical and informed, use of images in archaeological inquiry. The authors in this volume take on this challenge to question the way images have been used to frame collective visions of the past and to demonstrate the importance of a critical approach to historical images in archaeological inquiry.

Visual representations are productive vehicles for anthropological research. Historical archaeologists often use historical images, photographs, paintings, and illustrations in interpretations of past life and peoples. Barbara Little (1992:219) states, "The idea of image is useful for pulling together representations or reifications of the world." Clearly, one of the great advantages of historical archaeology is the opportunity to draw from a rich and diverse body of sources that includes material culture, texts, and historical images. While critics argue that images are not often subject to the same kinds of critical scrutiny as text or material culture, a growing number of historical archaeologists are mindful of the critical use of historical images in their interpretations. Such uses have an impact as the choices being made by historical archaeologists are influencing the course of visual representations in the field. This volume seeks to illuminate some of the current pathways being employed by historical archaeologists in North America, Europe, and the Middle East. 
Recognizing that visual representations are not just objects to be seen or purely subjects to study is the central tension for consideration of visual representations as being between art and artifact. This introductory chapter briefly defines, outlines, and reflects on some of the uses of visual representations in historical archaeology. The following papers outline some of the strategies used by historical archaeologists working around the globe.

\section{Historic Images}

The realm of what can be considered "historic images" is quite broad and can include paintings, illustrations, maps, and photographs. Historic images derive from uniquely different processes: painting, lithography, photography, etc., each with its own set of aesthetic and technical procedures. Historic images may stand alone, such as paintings, or they may be part of a larger work, such as illustrations taken from a text. They may have been published for a broad audience, or the audience may have been confined to a few individuals. These source concerns about images mirror those of using historical texts, but, as images carry with them a different weight, they differ regarding process and impact. Yet, from the viewpoint of historical archaeology, the use of images is often tied closely to the use of historical texts.

Historical archaeologists commonly divide their data into materials recovered from excavations versus those from archival resources, which, among other materials, include probate inventory lists, diaries, censuses, maps, and paintings. Methodologically, several approaches to using such resources exist. Mark Leone and Parker Potter (1988) present the two traditional approaches to the use of documents and archaeology in the research of historical archaeologists. One approach is to use documents to identify a site (e.g., this homelot belonged to person $X$, according to the land deeds). The second approach is to use archaeological investigations to fill in voids or provide details for the historical record (e.g., here in the ground is the story of $Y$, a story ignored in extant texts). Both of these approaches assume that the documents and archaeological records are linked. By unlinking the two, the possibility for exploring each approach expands. The archaeological record is read as a text, and archival resources are analyzed as material culture. Mary Beaudry (1988) and Little (1992), among others, explore the use of texts in historical archaeology. More lines of evidence are encouraged, allowing a great variety of archival resources to be employed for historical archaeology.

In considering the use of visual representations in historical archaeology, a partition exists between images used as data versus those critically examined as artifacts. An example of that duality is evident in The Times of Their Lives, a presentation of the archaeology of early colonial Massachusetts by James Deetz and Patricia Deetz (2000:66,70). One category is John Smith's 1616 map of New England and William Bradford's plan for Plymouth. These are visual representations used as documents, resources from the time period that help the archaeologist reconstruct the past landscape. The other use of visual representations is the critical consideration of 19th- and early-20thcentury paintings that Deetz and Deetz (2000: 12-13) use as evidence for the creation of the Pilgrim myth. The paintings are used to good effect to show the assumptions made about the early colonial past. The representations are ideological. Deetz and Deetz follow the lead of critical archaeologists (Handsman and Leone 1989) who use exhibits as foils for challenging assumptions about the recent past. That approach treats visual representations as artifacts, objects to be critically evaluated and interpreted. Some images are data, particularly helpful for locating features and gaining a sense of what a place looked like. Other representations are artifacts of contemporary power relations. Both approaches have their place in historical archaeology.

\section{Images with History}

Multidimensional understandings of visual representations in historical archaeology depict images as more than illustrations; the context in which images were created, their audience(s), and the methods of dissemination are important concepts to consider in an archaeological interpretation.

First is the concern for context, whose definition in regard to images differs from use of the term in archaeological inquiry. As Julia King (this volume) notes, artistic context includes the 
types and associations of behaviors and material culture as well as the social and cultural circumstances of an image's production. Archaeological context refers to the associations of artifacts, features, and stratigraphy. Each historical image was produced in a particular social and political context, which may influence the artist or maker of the image. At times, images tell us more about the maker of the image than about the subject itself. For example, 18th-century images of Native Americans and Africans in colonial Louisiana produced by the French colonist Alexander de Batz were compiled in a period of imperial expansion along with scientific and popular curiosity about New World as the "other." Although artists may have their own agendas, their decisions are rarely idiosyncratic, as they may also be commissioned or otherwise persuaded to produce a particular image. In addition, existing images and aesthetic conventions of the time may have impacted composition and the way in which artists depicted bodies, landscapes, or other imagery. Some subjects are underrepresented or not represented in images, and these omissions from the visual record often result in historical silences about these subjects, silences that often extend into assumptions about the trajectories to the present day (Trouillot 1995). Every historical image presents a particular reality. Some are subjective, some are imagined, while others are involved with real people and things in real time (Edwards 2001:2). Given the nuances of images, they cannot be reduced to a totalizing experience, nor do they function as windows to the past.

Such considerations scratch the surface of concerns regarding the context of image production, but all considerations factor in choices made regarding how to use such images in archaeological interpretations. Following from these considerations regarding context, archaeologists must also be concerned with audience as well as with the dissemination and consumption of historical images. The producers of an image (be it Harpers Weekly or an 18th-century European traveler) often had a specific audience in mind when constructing and producing it. More often than not, this intended audience included elite, literate peoples. Historical images were disseminated, however, to a wider audience than originally intended. Further, historical images were used (and continue to be mobilized) in particular contexts. Attention to audience high- lights the meaning of the visual representations and the implications of their use in the past and present. Recognizing that coarse earthenwares have not received attention in studies of the Irish past, Charles Orser (2001) uses a series of 19th-century paintings that show the horror of the Great Famine. Focusing on ceramic vessels in the representations, he locates the functional and symbolic aspects of the pottery. In conjunction with archaeological findings, Orser (2001: 99) argues for the need to give more attention to the represented material culture, objects that are a "metaphor for traditional Ireland" and are important to include with other symbols of Ireland, like the shamrock.

Over time and even to the present day, historical images were reproduced for a wide audience (both socially and economically), so others could imagine people, things, and landscapes of the past. For example, Patricia Rubertone (2001) describes how 18th- and 19th-century romanticized images of Roger Williams memorialized and visually transformed the historical representation of this controversial 17th-century figure. These images depicted the Narragansett Indians alongside Williams, similarly romanticized and biased, leaving a lasting impression on public and academic audiences.

Likewise, postcolonial images of people, events, and landscapes were reproduced in travelogues, advertisements, and newspaper accounts. Audience for and the dissemination of images are again key notions to investigate. Lauren Cook (2000) analyzed 19th- and 20th-century photographs of New York street life in the Five Points neighborhood. He highlights the notions of class, ethnicity, and the slums that resonate from such images, which not only impact social understanding of this past space but also social policy regarding the people who lived in that space. Not surprisingly, Martin Scorsese's cinematic vision of Five Points in Gangs of New York pulled from these images (rather than the extensive historical and archaeological research on this area) to further cement biased, popularized visions of 19th-century life (Yamin 2001).

\section{A Global Historical Archaeology Illustrated}

The authors in this volume draw on issues raised by other historical archaeologists. While 
they focus on different parts of the world, they all share the same overall concern regarding the complexity of imagery: all images are cultural constructs. Even photographs and maps, which are assumed to be more realistic, even objective, do not reproduce reality but, rather, their own particular reality. Archives, as repositories for historical images, are further marked by their own particular silences and biases as some images were destroyed, lost, or otherwise discarded. Whether intentional or unintentional, such deletions from archives result in an uneven visual record. It is here that archaeology plays an important role, helping fill out the gaps or even contradicting what is found in historical images. The contributions to this issue expand the consideration of visual representations in historical archaeology. The range of studies presented here illustrates the global aspects of the concerns with images.

\section{Acknowledgments}

We would like to thank the contributors of this issue for considering these topics along with us and presenting their excellent work here.

\section{References}

BeAudry, Mary C. (EDITOR)

1988 Documentary Archaeology in the New World. Cambridge University Press, Cambridge, England.

COOK, LAUREN J.

2000 The Construction of a Slum: A Visual Archaeology of Five Points. In Tales of Five Points: Working-Class Life in Nineteenth-Century New York, Vol. 2, Rebecca Yamin, editor, pp. 460-499. John Milner Associates, West Chester, PA.

Deetz, James, and Patricia S. Deetz

2000 The Times of Their Lives: Life, Love, and Death in Plymouth Colony. W. H. Freeman and Company, New York, NY.

\section{EDWARds, ELIZABETH}

1992 Anthropology and Photography: 1860-1920. Yale University Press, New Haven, CT.

2001 Raw Histories: Photographs, Anthropology, and Museums. Berg, Oxford, England.
Galloway, Patricia K.

1991 The Archaeology of the Ethnohistorical Narrative. In Colombian Consequences, Vol. 3, The Spanish Borderlands in Pan-American Perspective, D. H. Thomas, editor, pp. 453-469. Smithsonian Institution Press, Washington, DC.

Handsman, Russell, and Mark P. Leone

1989 Living History and Critical Archaeology in the Reconstruction of the Past. In Critical Traditions in Contemporary Archaeology, Valerie Pinsky and Allison Wylie, editors, pp. 104-116. Cambridge University Press, Cambridge, England.

Leone, Mark P., and Parker B. Potter, Jr.

1988 Introduction: Issues in Historical Archaeology. In The Recovery of Meaning: Historical Archaeology in the Eastern United States, Mark P. Leone and Parker B. Potter, Jr., editors, pp. 1-22. Smithsonian Institution Press, Washington, DC.

Little, Barbara (editor)

1992 Text-Aided Archaeology. CRC Press, Boca Raton, LA.

\section{MacDougall, David}

1997 The Visual in Anthropology. In Rethinking Visual Anthropology, Marcus Banks and Howard Murphy, editors, pp. 276-295. Yale University Press, New Haven, CT.

Moser, Stephanie

2001 Archaeological Representation: The Visual Conventions for Constructing Knowledge about the Past. In Archaeological Theory Today, Ian Hodder, editor, pp. 262-283. Polity Press, Cambridge, England.

Orser, Charles

2001 Vessels of Honor and Dishonor: The Symbolic Character of Irish Earthenwares. New Hibernia Review 5(1):83-100.

PInNey, Christopher

1997 Camera Indica: The Social Life of Indian Photographs. University of Chicago Press, Chicago, IL.

Rubertone, PAtricia

2001 Grave Undertakings: An Archaeology of Roger Williams and the Narragansett Indians. Smithsonian University Press, Washington, DC.

Stahl, Ann Brower

1993 Concepts of Time and Approaches to Analogical Reasoning in the Historical Perspective. American Antiquity 58(2):235-260.

Trouillot, Michel-Rolph

1995 Silencing the Past: Power and the Production of History. Beacon Press, Boston, MA. 
YAMIN, REBECCA

2001 Becoming New York: The Five Points Neighborhood. Historical Archaeology 35(3):1-5.

Diana DiPaolo Loren

Peabody Museum of Anthropology and

ETHNOLOGY

HARVARD UNIVERSITY

11 Divinity Avenue

CAMbridge MA 02138

\section{UZI BARAM}

Division of Social Sciences

New College of Florida

5700 North TAMiami Trail

SARAsota, FL 34243 